\title{
Mottling Incidence and Mottling Score According to Arterial Lactate Level in Septic Shock Patients
}

\author{
Arnaud Ferraris $^{1}$, Camille Bouisse ${ }^{2}$, Fabrice Thiollière ${ }^{3}$, Vincent Piriou ${ }^{4}$, Bernard Allaouchiche ${ }^{5}$
}

\begin{abstract}
Objectives: Mottling score is estimated from 0-5 according to mottling over the knee and described as clinical evaluation of tissue perfusion. This score was developed with ancient definitions of sepsis without lactate level, a major prognostic parameter when superior to $2 \mathrm{mmol} / \mathrm{L}$. This study describes mottling incidence and mottling score in septic shock patients according to lactate level.

Materials and methods: We reanalyzed our prospective study in a French tertiary hospital in the intensive care unit (ICU) which studied mottling score and thermography correlation. Patients admitted to septic shock diagnosis and requiring vasoactive drugs were included. We recorded hemodynamic variables, mottling score, and lactate. Data collection was realized at ICU admission (H0) and after six hours (H6).

Results: Forty-three patients were included. Mean age was $67( \pm 4)$, mean sequential organ failure assessment (SOFA) score was 11 (8-12), and SAPS II $58 \pm 20$. Mortality rate at day 28 was $30 \%$. Among patients with lactate $\geq 2 \mathrm{mmol} / \mathrm{L}$, mottling was more prevalent in $82.6 \%$ vs $47.4 \%$ ( $p$ value $=0.016)$, and at $\mathrm{H} 6$ mottling score was higher $(p$ value $=0.009)$. Although, mottling incidence was not different between dead $(85 \%)$ and survivors $(81 \%$; $p$ value $=0.795)$.

Conclusion: A new sepsis definition implies a new epidemiology in mottling according to lactate threshold. Patients with lactate $\geq 2 \mathrm{mmol} / \mathrm{L}$ presented a higher incidence and score of mottling. However, mortality was not influenced by mottling in this study.

Clinical significance:

- Arterial lactate is a major prognostic parameter when superior to $2 \mathrm{mmol} / \mathrm{L}$.

- A new definition of sepsis was published in 2016 with a new paradigm and epidemiology of septic shock

- Patients with lactate $\geq 2 \mathrm{mmol} / \mathrm{L}$ presented a higher incidence and score of mottling.

- Mottling score is a clinical sign of microcirculatory alteration, related to lactate level in septic shock.

Keywords: Lactate, Microcirculation, Mottling score, Septic shock.

Indian Journal of Critical Care Medicine (2020): 10.5005/jp-journals-10071-23531
\end{abstract}

\section{INTRODUCTION}

Microcirculation is a vascular network responsible for the distribution of oxygen from arteries to capillaries and tissues of the body. ${ }^{1}$ In septic shock, peripheral perfusion is altered, generating hypoxia and organ failure. ${ }^{2}$ Many studies explored microcirculatory alterations, a crucial point in physiopathology of septic shock. ${ }^{3,4}$ Microcirculation evaluation is feasible at bedside with capillary refill time, mottling score, diuresis, or skin temperature gradients. Nevertheless, technical devices are in development to direct evaluation of microvascular perfusion, such as sublingual videomicroscopy with sidestream dark field (SDF) ${ }^{5}$ or near-infrared spectroscopy technology (NIRS) that indirectly evaluates tissue perfusion and global oxygenation alteration. ${ }^{6}$ None of these devices has showed superiority on the other. No gold standard is available to compare these methods, which makes microcirculation monitoring uneasy. We decided to focus on skin perfusion of the knee by mottling score, basing our choice on previous studies. ${ }^{7}$

Skin mottling is defined as a violaceous coloration due to blood flow reduction in small vessels secondary to heterogeneous microcirculation alterations. An example is depicted in Figure 1 with schematized 5 mottling areas. In a previous observational study, skin mottling ratio reached $29 \%$ in an intensive care unit (ICU) population of 791 patients and increased to $49 \%$ in patients admitted for septic shock. Specific scores such as SAPS II were higher in patients with mottling in comparison to those free of mottling [mean SAPS II 46 (34-59) vs 32 (21-45), respectively]..$^{8}$ Mottling is
${ }^{1-5}$ Department of Service d'anesthésie Reanimation, Hospices Civils de Lyon, Pierre-Bénite, France

Corresponding Author: Arnaud Ferraris, Department of Service d'anesthésie Reanimation, Hospices Civils de Lyon, Pierre-Bénite, France, Phone: +33472357595, e-mail: arnaud.ferraris@chu-lyon.fr

How to cite this article: Ferraris A, Bouisse $C$, Thiollière F, Piriou V, Allaouchiche B. Mottling Incidence and Mottling Score According to Arterial Lactate Level in Septic Shock Patients. Indian J Crit Care Med 2020;24(8):672-676.

Source of support: Nil

Conflict of interest: None

a clinical sign of septic shock, ${ }^{2}$ easy to recognize over the knee in ICU or in emergency settings and identified as a negative outcome in critically ill patients. ${ }^{9}$

A new definition of sepsis was published in 2016 with a septic shock defined by a sepsis associated with lactate $\geq 2 \mathrm{mmol} / \mathrm{L}$ and vasopressor requirement to maintain mean arterial pressure $(\mathrm{MAP}) \geq 65 \mathrm{~mm} \mathrm{Hg} .^{10}$ A new definition implies a new paradigm and repartition in septic shock epidemiology. As a major prognostic parameter, we presumed that patients with arterial lactate $\geq 2$ $\mathrm{mmol} / \mathrm{L}$ present more microcirculatory disorders such as mottling.

We analyzed our data issued from our prospective observational study, including all patients admitted in the ICU for septic shock 
which compared mottling score with skin temperature around the knee involving infrared thermography. ${ }^{11}$ The objective of the current study is to analyze mottling incidence and mottling score in septic shock patients according to lactate threshold of $2 \mathrm{mmol} / \mathrm{L}$.

\section{Materials and Methods}

We resumed data of our prospective cohort of 46 patients published in $2018^{11}$ which focused on correlation between skin temperature measured by thermography with mottling score during septic shock. Briefly, we achieved over 8-month period a prospective observational study in an ICU in a French tertiary hospital of Lyon from January to August 2016. We enrolled adult consecutive patients with a diagnosis of septic shock. Patients were enrolled with a suspected sepsis associated with systolic arterial pressure $<90 \mathrm{~mm} \mathrm{Hg}$ or MAP $<65 \mathrm{~mm} \mathrm{Hg}$, despite initial crystalloid resuscitation and requiring norepinephrine at admission

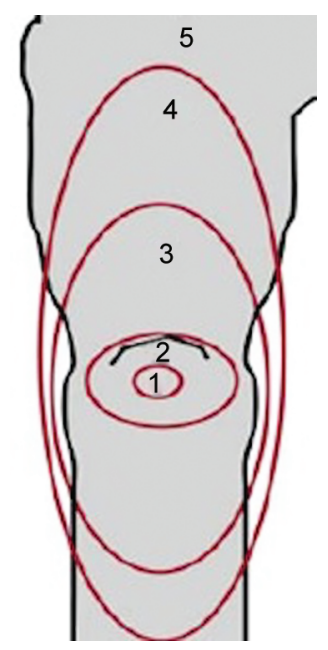

Fig. 1: Mottling score defined by five zones around the knee. Schema from Ref. 9 in ICU. Those excluded include black skin, pregnancy, peripheral arterial disease, cutaneous infection of the lower limbs, and patient or relatives refusal. This study was purely observational, and verbal information was authorized (local ethics committee). Oral information was given to all patients. Institutional approval was issued from the local ethics committee (Comité de Protection des Personnes sud est IV Lyon, France; Ref L15-2013, approved on December 15 of 2015).

\section{Management of Patients}

Patient care with septic shock was guided according to local protocol and adapted from reference guidelines. ${ }^{10,12}$ Briefly, patient resuscitation at admission was intravenous volume expansion with crystalloids and initiation of vasoactive drugs (norepinephrine) to reach specified end points: MAP $>65 \mathrm{~mm} \mathrm{Hg}$ (or $70 \mathrm{~mm} \mathrm{Hg}$ in patients with chronic arterial hypertension) and urine output $>0.5$ $\mathrm{mL} / \mathrm{kg} /$ hour. Continuous and invasive arterial pressure, central venous catheter, and mechanical ventilation were provided when needed. We used transthoracic echocardiography (Vivid S6, General Electric Healthcare ${ }^{\circledast}$ ) or transpulmonary thermodilution (PiCCO, Pulsion medical system ${ }^{\circledast}$ ) as hemodynamic monitoring. According to local protocol, sedation and analgesia were performed with midazolam and sufentanil, respectively.

\section{Study Protocol}

Demographic and clinical characteristics of the patients were recorded: age, sex, severity scores with sequential organ failure assessment (SOFA) and Simplified Acute Physiologic Score II (SAPS II) determined at admission. ${ }^{13,14}$ Measurements were performed at study inclusion $(\mathrm{HO})$ and 6 hours after initial resuscitation ( $\mathrm{H6}$ ): global macrocirculatory variables (MAP, heart rate, and cardiac output), arterial lactate, mechanical ventilation, norepinephrine requirements, and mottling score (from 0 to 5 ). Thermography was realized with a thermic camera FLIR- ${ }^{\oplus}$ at $\mathrm{HO}$ and $\mathrm{H} 6$ at bedside for the previous analysis (Fig. 2). We recorded ICU mortality rate at day 28 , length of stay, mechanical ventilation-free days, and SOFA score on discharge.

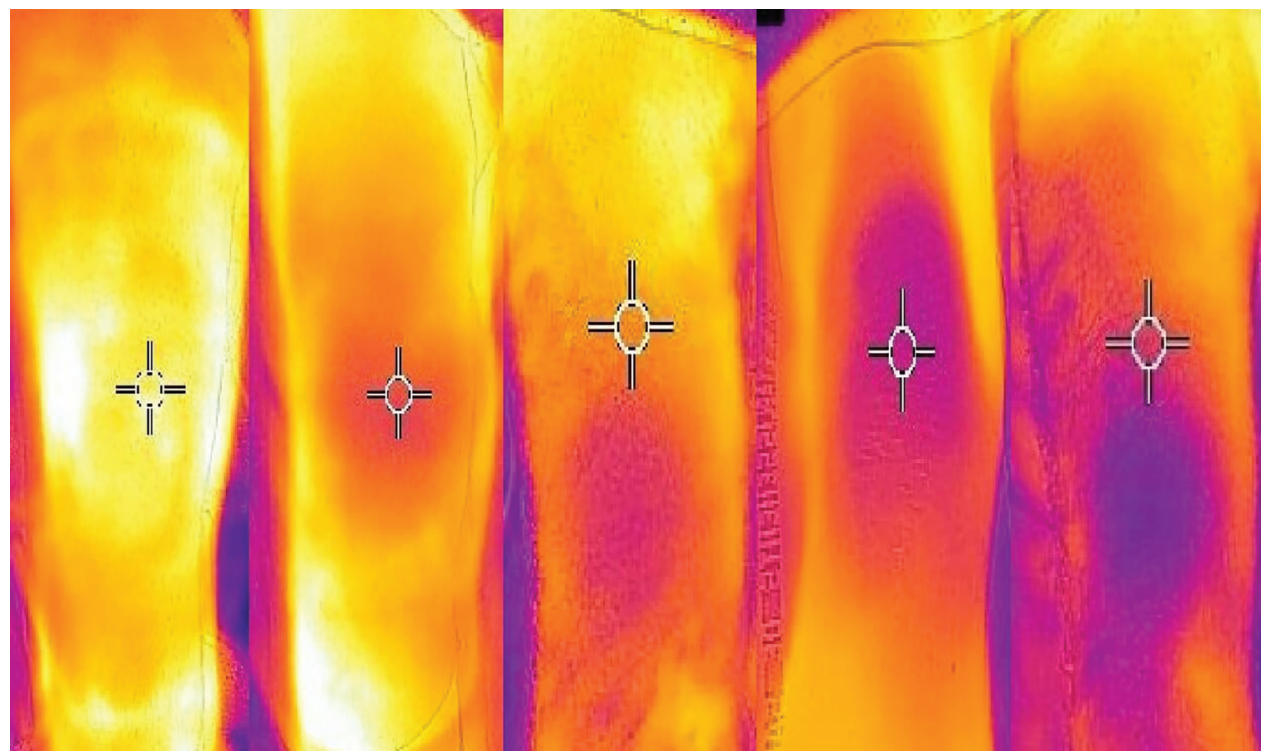

Fig. 2: Examples of thermography, from mottling score $0-4$ (from left to right) 


\section{Endpoints}

Primary endpoint is a difference in mottling incidence and mottling score according to arterial lactate level during a septic shock. We supposed that patients with lactate $\geq 2 \mathrm{mmol} / \mathrm{L}$ presented higher mottling frequency and higher mottling score than patients with lactate $<2 \mathrm{mmol} / \mathrm{L}$.

Secondary endpoints are first to compare hemodynamic parameters and vasopressor requirements according to lactate level and second the relationship between mottling and ICU mortality, 28-day survival, severity scores at admission and discharge, and norepinephrine level.

\section{Statistical Analysis}

Data are presented as number (\%), mean \pm SD (standard deviation) or median (25th-75th) for non-normally distributed variables (Shapiro-Wilk test) as appropriate. A Chi-square test and a student test were performed to compare patients with a lactate $\geq 2 \mathrm{mmol} / \mathrm{L}$ or inferior. A $p$ value $<0.05$ was considered statistically significant. Statistical analysis was performed using JMP 13.1 software (SAS institute).

\section{Results}

Forty-six patients were prospectively included for septic shock during an 8-month period in the ICU. Clinical characteristics of the patients are summarized in Table 1. Save 3 patients weaned from vasopressors at $\mathrm{H} 6$ time point after initial resuscitation, and all patients received norepinephrine. ICU mortality was 30\% $(n=14)$.

We compared hemodynamic parameters, mottling, and prognostic factors between patients with an arterial lactate $\geq 2$

Table 1: General characteristics. Values are expressed as absolute values $(n), \%$, mean $( \pm$ SD) or median (25th-75th)

\begin{tabular}{|c|c|c|}
\hline Patients $(n)$ & 46 & \\
\hline Age, years & $67( \pm 4)$ & \\
\hline Male gender & $21(45 \%)$ & \\
\hline Body mass index $\left(\mathrm{kg} / \mathrm{m}^{2}\right)$ & $25( \pm 2)$ & \\
\hline SOFA at admission & $11(8-12)$ & \\
\hline SAPS II at admission & $57( \pm 20)$ & \\
\hline Hemodynamic parameters & $\mathrm{HO}$ & H6 \\
\hline $\begin{array}{l}\text { Mean arterial pressure } \\
(\mathrm{mm} \mathrm{Hg})\end{array}$ & $67( \pm 5)$ & $73( \pm 12)$ \\
\hline Heart rate (/minute) & $101( \pm 9)$ & $97( \pm 7)$ \\
\hline $\begin{array}{l}\text { Cardiac output (mL/ } \\
\text { minute) }\end{array}$ & $4.9(4.5-5.4)$ & $5.1(4.2-5.7)$ \\
\hline $\begin{array}{l}\text { Mottling at examination, } \\
n / \text { total }\end{array}$ & $25 / 37$ (68\%) & $29 / 43(67 \%)$ \\
\hline Volume expansion (mL) & $1,000(750-2,250)$ & $1,000(100-2,000)$ \\
\hline $\begin{array}{l}\text { Norepinephrine doses } \\
\text { ( } \mu \mathrm{g} / \mathrm{kg} / \text { minute) }\end{array}$ & $0.37(0.13-0.8)$ & $0.42(0.15-0.9)$ \\
\hline Lactate level (mmol/L) & $2.4(1.2-4.7)$ & $2.2(1.4-4)$ \\
\hline Mechanical ventilation & $31(67 \%)$ & \\
\hline \multicolumn{3}{|l|}{ Outcomes } \\
\hline 28-day mortality & $14(30 \%)$ & \\
\hline ICU length-of-stay, days & $12(5-24)$ & \\
\hline SOFA at ICU discharge & $2(0-6)$ & \\
\hline Vasopressor-free days & $4.5(1-11)$ & \\
\hline Ventilator-free days & $3(1-6)$ & \\
\hline
\end{tabular}

$\mathrm{mmol} / \mathrm{L}$ and those with a lactate $<2 \mathrm{mmol} / \mathrm{L}$. Results are presented in Table 2 for $\mathrm{HO}$ (ICU admission) and in Table 3 for $\mathrm{H} 6$.

Among patients with arterial lactate $\geq 2 \mathrm{mmol} / \mathrm{L}$ at $\mathrm{H} 0,77 \%$ of nonsurvivors presented mottling vs $72 \%$ in survivors ( $p$ value $=$ $0.795)$. Similarly, at $\mathrm{H} 685 \%$ of nonsurvivors presented mottling vs $81 \%$ in survivors ( $p$ value $=0.795$ ).

\section{Discussion}

We resumed analysis from our cohort of a prospective observational study to describe mottling incidence and mottling score in septic shock patients according to lactate threshold of $2 \mathrm{mmol} / \mathrm{L}$. In this analysis, mottling repartition was different at $\mathrm{H} 6$ according to arterial lactate level. Patients with a lactate $\geq 2 \mathrm{mmol} / \mathrm{L}$ required higher norepinephrine doses, mottling incidence, and mottling score at H6. Furthermore, no difference was demonstrated in this study with severity score such as SOFA and day-28 mortality.

Skin temperature is a paramount parameter in microcirculation monitoring, including other exploration such as capillary refill time, where normal threshold is debated..$^{15}$ Most of the studies focused on septic shock, ${ }^{16,17}$ and they confirmed microvascular alterations. Nevertheless, microcirculatory alterations are described in various critical situations: cardiogenic shock ${ }^{18}$ and severe trauma. ${ }^{19}$ In the present study, we focused on septic shock to generate a homogeneous cohort with the physiopathology of sepsis.

Many microcirculation analyzes are published, some are clinical assessments easy to perform at bedside but often subjective measures: capillary refill time, ${ }^{20}$ toe-to-room temperature gradients, ${ }^{21}$ and mottling score. ${ }^{9}$ Some devices are developed as videomicroscopy, spectral orthogonal polarization, or side stream dark field imaging to directly visualization of microcirculation. ${ }^{5}$ However, these techniques are not daily practice and remain in development. Moreover, in absence of gold standard, we focus on mottling score that is an easy and simple exploration. Initially developed by Ait-Oufella, this exploration is correlated with mortality and ICU outcomes in septic shock in a single-center study. ${ }^{9}$ Among 60 patients in septic shock, the authors established a strong

Table 2: Hemodynamic parameters, mottling score at ICU admission (H0) according to lactate level. Values are expressed as absolute values $(n), \%$, mean $( \pm \mathrm{SD})$ or median (25th-75th)

\begin{tabular}{|c|c|c|c|}
\hline HO (admission) & $\begin{array}{l}\text { Lactate } \\
\geq 2 \mathrm{mmol} / \mathrm{L}\end{array}$ & $\begin{array}{l}\text { Lactate } \\
<2 \mathrm{mmol} / \mathrm{L}\end{array}$ & $p$ value \\
\hline SOFA score & $10.5(8-12)$ & $10(6-12)$ & 0.578 \\
\hline Hemodynamic SOFA & $4(4-4)$ & $4(4-4)$ & 0.578 \\
\hline MAP $(\mathrm{mm} \mathrm{Hg})$ & $61 \pm 6$ & $76 \pm 7$ & 0.001 \\
\hline Heart rate (/minute) & $107 \pm 13$ & $91 \pm 12$ & 0.084 \\
\hline $\begin{array}{l}\text { Norepinephrine doses } \\
\text { ( } \mu \mathrm{g} / \mathrm{kg} / \text { minute) }\end{array}$ & $0.69(0.14-1)$ & $0.26(0.12-0.4)$ & 0.033 \\
\hline Mottling patients $(n)$ & $75 \%$ & $69 \%$ & 0.716 \\
\hline \multicolumn{4}{|l|}{ Mottling score } \\
\hline 0 & $25 \%$ & $31 \%$ & \\
\hline 1 & $20 \%$ & $23 \%$ & \\
\hline 2 & $25 \%$ & $31 \%$ & \\
\hline 3 & $20 \%$ & $15 \%$ & \\
\hline 4 & $10 \%$ & $0 \%$ & \\
\hline 5 & $0 \%$ & $0 \%$ & 0.805 \\
\hline 28-day mortality (n) & $45 \%$ & $23 \%$ & 0.21 \\
\hline
\end{tabular}


Table 3: Hemodynamic parameters, mottling score after initial resuscitation $(\mathrm{H} 6)$ according to lactate level. Values are expressed as absolute values $(n), \%$, mean ( \pm SD) or median (25th-75th)

\begin{tabular}{llll}
\hline H6 & $\begin{array}{l}\text { Lactate } \geq 2 \\
\mathrm{mmol} / \mathrm{L}\end{array}$ & $\begin{array}{l}\text { Lactate }<2 \\
\mathrm{mmol} / \mathrm{L}\end{array}$ & $\mathrm{p \text {value }}$ \\
\hline MAP $(\mathrm{mm} \mathrm{Hg})$ & $74 \pm 5$ & $73 \pm 5$ & 0.634 \\
$\begin{array}{l}\text { Heart rate } / \text { minute) } \\
\text { Norepinephrine }\end{array}$ & $100 \pm 10$ & $95 \pm 13$ & 0.551 \\
doses $(\mu \mathrm{g} / \mathrm{kg} /$ minute $)$ & $0.75(0.36-1.1)$ & $0.18(0.06-0.45)$ & 0.006 \\
Mottling patients $(n)$ & $86.2 \%$ & $47.4 \%$ & 0.016 \\
Mottling score & & & \\
0 & $17.4 \%$ & $52.6 \%$ & \\
1 & $43.5 \%$ & $0 \%$ & \\
2 & $17.4 \%$ & $21.1 \%$ & \\
3 & $13 \%$ & $21.1 \%$ & \\
4 & $8.7 \%$ & $0 \%$ & \\
5 & $0 \%$ & $5.3 \%$ & 0.009 \\
28 -day mortality $(n)$ & $30.4 \%$ & $25 \%$ & 0.692 \\
\hline
\end{tabular}

relation between 14-day mortality and mottling score ( $p$ value $<$ 0.0001 ) as well as its variation between admission $\mathrm{HO}$ and $\mathrm{H} 6$.

In this study, $\mathrm{HO}$ and $\mathrm{H} 6$ time points were empirically determined similar to previous studies ${ }^{9,22}$ when measures were related to mortality. At $\mathrm{HO}$, we expect the worst microcirculation situation and at $\mathrm{H} 6$ a stabilization after initial resuscitation.

This current work is the first study to analyze mottling score according to new sepsis definition. As a meta parameter of severity of septic shock, arterial lactate is related to circulatory and metabolic disorders. This study confirms relationship between arterial lactate and peripheral circulatory disorders, such as mottling. Nevertheless, no correlation was found between ICU outcomes or mortality and arterial lactate groups. This point corroborates the lack of power hypothesis in our study. Negative results could be explained with a limited cohort. Moreover, the study was not designed to establish relationship between mottling and mortality but to compare mottling score distribution according to lactate threshold, and this work is a second analysis of a previous study designed to another objective. We note some limitations to illustrate the lack of results: We conducted a monocentric study, and number of patients is limited without previous calculation of the number of subjects required. This study was neither randomized nor blinded. Moreover, mottling score is not a gold standard in microcirculatory monitoring. Other studies are required to confirm these data with a larger cohort. Measurement and comparison of others microcirculatory parameters, such as capillary refill time, temperature gradients between central to peripheral, and vascular occlusion test with a NIRS device according to lactate threshold, are further studies to be conducted.

\section{Conclusion}

A new sepsis definition implies a new epidemiology in mottling according to lactate threshold. Patients with lactate $\geq 2 \mathrm{mmol} / \mathrm{L}$ presented a higher incidence and score of mottling. However, mortality was not influenced by mottling in this study.

\section{Availability of Data and Material}

Data are available in Data Archiving and Networked Services: https://doi.org/10.17026/dans-za5-xs39

\section{REFERENCES}

1. Vincent J-L, De Backer D. Microvascular dysfunction as a cause of organ dysfunction in severe sepsis. Crit Care Lond Engl 2005;9(Suppl 4):S9-S12. DOI: $10.1186 / \mathrm{cc} 3748$.

2. Vincent J-L, De Backer D. Circulatory shock. N Engl J Med 2013;369(18):1726-1734. DOI: 10.1056/NEJMra1208943.

3. Ince C. The microcirculation is the motor of sepsis. Crit Care Lond Engl 2005;9(Suppl. 4):S13-S19.

4. De Backer D, Creteur J, Preiser J-C, Dubois M-J, Vincent J-L. Microvascular blood flow is altered in patients with sepsis. Am J Respir Crit Care Med 2002;166(1):98-104. DOI: 10.1164/rccm.200109-016oc.

5. De Backer D, Ospina-Tascon G, Salgado D, Favory R, Creteur J, Vincent J-L. Monitoring the microcirculation in the critically ill patient: current methods and future approaches. Intensive Care Med 2010;36(11):1813-1825. DOI: 10.1007/s00134-010-2005-3.

6. Lima A, van Bommel J, Sikorska K, van Genderen M, Klijn E, Lesaffre $E$, et al. The relation of near-infrared spectroscopy with changes in peripheral circulation in critically ill patients. Crit Care Med 2011;39(7):1649-1654. DOI: 10.1097/CCM.0b013e3182186675.

7. Ait-Oufella H, Bourcier S, Alves M, Galbois A, Baudel J-L, Margetis D, et al. Alteration of skin perfusion in mottling area during septic shock. Ann Intensive Care 2013;3(1):31. DOI: 10.1186/2110-5820-3-31.

8. Coudroy R, Jamet A, Frat J-P, Veinstein A, Chatellier D, Goudet V, et al. Incidence and impact of skin mottling over the knee and its duration on outcome in critically ill patients. Intensive Care Med 2015;41(3):452-459. DOI: 10.1007/s00134-014-3600-5.

9. Ait-Oufella H, Lemoinne S, Boelle PY, Galbois A, Baudel JL, Lemant J, et al. Mottling score predicts survival in septic shock. Intensive Care Med 2011;37(5):801-807. DOI: 10.1007/s00134-011-2163-y.

10. Singer M, Deutschman CS, Seymour CW, Shankar-Hari M, Annane D, Bauer $M$, et al. The third international consensus definitions for sepsis and septic shock (sepsis-3). JAMA 2016;315(8):801-810. DOI: 10.1001/ jama.2016.0287.

11. Ferraris A, Bouisse C, Mottard N, Thiollière F, Anselin S, Piriou V, et al. Mottling score and skin temperature in septic shock: relation and impact on prognosis in ICU. PLoS ONE 2018;13(8):e0202329. DOI: 10.1371/journal.pone.0202329.

12. Dellinger RP, Levy MM, Rhodes A, Annane D, Gerlach H, Opal $\mathrm{SM}$, et al. Surviving sepsis campaign: International guidelines for management of severe sepsis and septic shock, 2012. Intensive Care Med 2013;39(2):165-228. DOI: 10.1007/s00134-012-2769-8.

13. Vincent JL, Moreno R, Takala J, Willatts S, De Mendonça A, Bruining $\mathrm{H}$, et al. The SOFA (sepsis-related organ failure assessment) score to describe organ dysfunction/failure. On behalf of the working group on sepsis-related problems of the European society of intensive care medicine. Intensive Care Med 1996;22(7):707-710. DOI: 10.1007/ BF01709751.

14. Le Gall JR, Lemeshow S, Saulnier F. A new simplified acute physiology score (SAPS II) based on a European/North American multicenter study. JAMA 1993;270(24):2957-2963. DOI: 10.1001/jama.270.24.2957.

15. Schriger DL, Baraff L. Defining normal capillary refill: variation with age, sex, and temperature. Ann Emerg Med 1988;17(9):932-935. DOI: 10.1016/s0196-0644(88)80675-9.

16. Ait-Oufella H, Bourcier S, Lehoux S, Guidet B. Microcirculatory disorders during septic shock. Curr Opin Crit Care 2015;21(4):271-275. DOI: $10.1097 / \mathrm{MCC} .0000000000000217$.

17. Miranda M, Balarini M, Caixeta D, Bouskela E. Microcirculatory dysfunction in sepsis: pathophysiology, clinical monitoring, and potential therapies. Am J Physiol Heart Circ Physiol 2016;311(1):H24H35. DOI: 10.1152/ajpheart.00034.2016.

18. De Backer D, Creteur J, Dubois M-J, Sakr Y, Vincent J-L. Microvascular alterations in patients with acute severe heart failure and cardiogenic shock. Am Heart J 2004;147(1):91-99. DOI: 10.1016/j.ahj.2003.07.006.

19. Lee Y-LL, Simmons JD, Gillespie MN, Alvarez DF, Gonzalez RP, Brevard SB, et al. Evaluation of microvascular perfusion and resuscitation after severe injury. Am Surg 2015;81(12):1272-1278. DOI: 10.1177/000313481508101231. 
20. Ait-Oufella H, Bige N, Boelle PY, Pichereau C, Alves M, Bertinchamp R, et al. Capillary refill time exploration during septic shock. Intensive Care Med 2014;40(7):958-964. DOI: 10.1007/s00134-014-3326-4.

21. Bourcier S, Pichereau C, Boelle P-Y, Nemlaghi S, Dubée V, Lejour $\mathrm{G}$, et al. Toe-to-room temperature gradient correlates with tissue perfusion and predicts outcome in selected critically ill patients with severe infections. Ann Intensive Care 2016;6(1):63. DOI: 10.1186/ s13613-016-0164-2.

22. Ait-Oufella H, Joffre J, Boelle PY, Galbois A, Bourcier S, Baudel JL, et al. Knee area tissue oxygen saturation is predictive of 14-day mortality in septic shock. Intensive Care Med 2012;38(6):976-983. DOI: 10.1007/ s00134-012-2555-7. 